\title{
A AD E A ORDEM PÓS-MODERNA ${ }^{1}$
}

\section{Atílio BUTTURI JUNIOR}

UFSC

Djane Antonucci CORREA

UEPG

Resumo: Este trabalho pretende, partindo da ordem do discurso de Foucault (2002) , debater as relações entre a Lingüística e a Epistemologia desde a autonomia moderna de seus campos no início do século XX até a assunção da exterioridade como constitutiva dos saberes, a fim de indicar as condições de emergência da Análise do Discurso (AD) no regime do dizer da episteme pós-moderna.

Palavras-chave: discurso; ordem; pós-modernidade.

Abstract: This paper intends, starting with Foucault's order (2002), to debate the relations between Linguistics and Epistemology, since the modern autonomy of their fields in the end of the twenty century until de assumption of the exterior as a part of the wisdoms, to indicate the emergency's conditions of the Discourse Analysis (DA) in the discourse regime of the post-modern episteme.

Key-words: discourse; order; post-modernity.

\section{Introdução}

A complexização do entendimento sistemático da linguagem e a respectiva tentativa de suplantação são compartilhadas de maneira decisiva a partir da década de cinqüenta nos estudos lingüísticos, sobretudo em três orientações: a pragmática, as teorias enunciativas e $\mathrm{a}(\mathrm{s})$ análise(s) do discurso.

Surgidas a partir do questionamento exterior ao campo lingüístico, tais perspectivas teóricas voltaram-se diretamente ao "núcleo duro" da ainda incipiente ciência da linguagem, apontando a simplicidade do descritivismo e um idealismo metodológico que fazia pensar os objetos alienados de suas condições de surgimento.

Assim como fizeram as ciências naturais desde Copenhagen e a necessidade de repensar os microfatores presentes em qualquer

\footnotetext{
${ }^{1}$ Este trabalho é resultado da pesquisa PIBIC/CNPq.
} 
operação dita científica, a Lingüística assume, a partir de meados da década de sessenta, uma postura complexizante, que terá variações importantes segundo o modelo a que se fará referência.

Diante dessas transformações, este trabalho elege como objeto específico a Análise do Discurso de Linha Francesa (doravante $\mathrm{AD})$, sobretudo pelo seu caráter indisciplinar que, não obstante as vicissitudes epistemológicas, oferece o recorte mais profícuo a uma caracterização inicial da configuração contemporânea do saber, que aqui apontará uma desejável - ainda que discutível - pós modernidade da ciência lingüística. Nesse perscrutar, o interesse é averiguar a própria possibilidade de emergência das problemáticas do discurso, refletindo sobre a constituição de seus objetos, conceitos e subjetividades operantes.

A fim de desenvolver algumas questões de AD, buscamos investigar as relações entre Epistemologia e Lingüística, partindo das respectivas autonomizações de campo até a constatação da exterioridade - tanto práticas sociais quanto discursos - como constitutiva de seus conhecimentos a fim de indicar as condições de emergência da AD no regime do dizer da episteme pós-moderna.

Seguindo alguns parâmetros de Foucault (2002), observamos como se efetua o cruzamento das descontinuidades entre diferentes campos do saber e como estes estão afetados tanto pela rarefação interna ao discurso quanto por princípios exteriores que circunscrevem um modo de enunciar no qual a heterogeneidade passa a ser paulatinamente valorizada.

\section{1 À procura da pós-modernidade}

Ainda que discordando de qualquer definição de pósmodernidade, ${ }^{2}$ Habermas (1990, p.15) vai indicar, na ultrapassagem

\footnotetext{
${ }^{2}$ Para o pensamento habermasiano, vinculado ao discurso das ciências sociais críticas de Frankfurt, negar a superação da experiência moderna é mesmo ratificar a postura de um metalugar do qual uma verdade poderá ser instituída. Conforme Ricoeur (1983, p. 128), "a crítica é essa teoria da competência comunicativa que engloba a arte de compreender, as técnicas para vencer a nãocompreensão e a ciência explicativa das distorções”. Discordando dessa "purificação" implícita, fazemos uso das descrições de Habermas (1990) que
} 
contemporânea da metafísica, a passagem de um paradigma da consciência para o de uma filosofia da linguagem, no qual:

As relaçôes entre linguagem e mundo, entre proposiçōes e estados de coisas, substituem as relacôes sujeito-objeto. O trabalho de constituição do mundo deixa de ser uma tarefa da subjetividade transcendental para se transformar em estruturas gramaticais.

Ultrapassando o idealismo kantiano, o pleno desenvolvimento dessas concepções teria sido realizado por aquela "guinada lingüística" que, não obstante o nascimento nos limites lógico-semanticistas (o formalismo de Russel e Frege), foi capaz de explorar "o potencial de solução do novo paradigma" (HABERMAS, 1990, p.55) no solo fértil das categorias sugeridas em Freud e Saussure, pelas quais se tornou exeqüível pensar as relações constitutivas entre o mundo e o sujeito sempre-já introduzido na língua e no desejo - e, junto com Marx, no trabalho - sendo impossibilitadas tanto as objetivações universalizantes dum sujeito cartesiano quanto suplantadas as discussões acerca dos princípios gnosiológicos gerais.

Relacionando, ademais, essas metamorfoses à pragmática formal de Wittgenstein/ Austin/ Searle, o filósofo frankfurtiano acrescentará a vantagem desta última da auto-referencialidade das ações lingüísticas, nas quais o TELOS do entendimento indicaria desde motivações (ilocução, perlocução) até os contextos enunciativos (HABERMAS, 1990).

Com isso, a própria referencialidade e sua especular questão do verdadeiro - ainda premente na semântica formal imediatamente precedente - deixariam espaço para um relativismo baseado nos valores enunciativos dos performativos. Conforme Austin (apud PINTO, 2001, p. 59): "Pode-se dizer de um ato que ele é útil, que é conveniente, que ele é mesmo sensato, não se pode dizer que ele seja true ou false. Qualquer que seja ele, tudo que posso dizer é que os enunciados desse tipo são muito mais numerosos e variados do que se acreditava".

versam sobre o pensamento pós-metafísico esvaziando-as das questões do "agir comunicativo" e das restrições a alguns teóricos da pós-modernidade. 
Destarte, se orientarmo-nos pela cisão da relação sujeitoobjeto substituída pela da linguagem-mundo de Habermas (1990), é produtivo que entendamos da destituição de um sujeito de tipo cartesiano - promovida pela "guinada lingüística" - a destituição do próprio projeto moderno de totalização das esferas do saber mediante a simplificação deliberada das relações do conhecimento que permitia alienar o poder das esferas de constituição e manutenção dos saberes.

Esta alternativa - inferida então como pós-moderna - é hipótese de trabalho de Lyotard (1998), para o qual a mudança de estatuto dos saberes está implicada nas transformações da era pósindustrial e das culturas ditas pós-modernas, cuja reflexão primeira é a dos saberes organizados como discursos e, portanto, alienados de sua capacidade de legitimação última (a incredulidade diante das metanarrativas).

Confrontando Habermas (1990) com Lyotard (1998), conclui-se que ambos responsabilizam o lingüístico como fundamento das transformações, bem como negativizam o estatuto da ciência. Em ambos, se instauraria uma abandono da autonomia dos sistemas significantes: é na materialidade das trocas lingüísticas que os objetos, os conceitos e as teorias se constroem, não havendo nem abstração neutra na constituição da linguagem, nem uso descontextualizado que lhe permitisse sentidos unívocos e sinonímias, não havendo metarrelatos totalizadores.

Entretanto, é uma diferença mais fundamental que os separa: enquanto Habermas vê na ciência um instrumento de reificação que poderá ser suplantado pelo interesse emancipatório e, por conseguinte, pelo agir comunicativo, portador de usos mais autênticos da linguagem, Lyotard assume o imperativo contextual diretamente proporcional ao caráter de contrato de qualquer mediação linguageira.

Assim, apesar da eleição da pós-modernidade como parâmetro para este texto, parece-nos possível observar as diferenciações no percurso da $\mathrm{AD}$ como alternâncias entre teorias que fazem uma psicanálise dos discursos, nos moldes habermasianos (há um lugar possível para a metalinguagem), e teorias que assumem contextualidade mais radical e, portanto, pós-moderna.

Consideraremos a pós-modernidade seguindo a negação radical das metalínguas, cuja conseqüência primeira seria a de uma inclusão constitutiva das exterioridades em toda sorte de saberes 
autônomos engendrada na modernidade. É uma espécie de revisionismo crítico que, atentando para a não-transparência das estruturas e sua vinculação necessária com a materialidade (práticas sociais e discursos), toma o sincretismo como saída necessária.

Destituindo, ainda, a história de sua teleologia pelo progresso - não há mais acumulação, mas incomensurabilidade, cada teoria não aprimorando a anterior mas ocupando seu espaço enunciativo e o poder correspondente -, é na própria concepção de um sujeito agente (hegelianamente, parte do todo que é o Espírito) e autônomo que o pós-moderno exercerá sua força: o sujeito tornando-se uma história da subjetivação, diretamente relacionada a uma configuração que o necessitava como suporte a fim de neutralizar o "dano". Ser sujeito era, então, corroborar a mítica das abstrações autônomas e progressistas.

Nossa hipótese é, pois, de uma "revolução" pós- moderna na Lingüística garantida sobretudo pelo surgimento da $A D$, tanto em sua negação da neutralidade estrutural quanto pela "contaminação" constitutiva que faria intervir sobre os sistemas.

Ao privilegiarmos o recorte $\mathrm{AD} /$ pós-modernidade, é mister que intentemos uma reconstrução histórica desse paradigma lingüístico, constitutivo de uma reviravolta epistemológica. Dada a implicação recíproca, elegeremos o binômio linguística-epistemologia, perscrutando semelhanças em suas trajetórias recentes que, apesar de não esgotarem um ZEITGEIST, sugerem um compartilhar de configuração epistêmica.

Desta forma, mesmo que possamos estender algumas modificações a outros campos (por exemplo, a literatura), é preciso insistir que não se trata de uma busca pela totalização, mas pelas condições de aparecimento de um saber particular, a AD.

Partindo de Rabuske (1987) e a conceituação da epistemologia como ramo da Teoria do Conhecimento cuja tarefa é a reconstrução das teorias científicas já existentes, acrescentemos as asserções de Santos (2000, p. 27) ao debate, sobretudo pela problematização de um paradigma pós-moderno que confere caracteres discursivos à epistemologia hodierna:

a reflexão epistemológica passa a incidir sobre os utilizadores [...] do discurso cientifico. E dado que as conseqüências deixam de ser o que está além da ciência para passarem a ser o que está para aquém da ciência, 
o universo dos utilizadores é constituído, tanto pelos cidadãos, como pelos cientistas e a reflexão epistemológica destinar-se-á a aumentar a competência lingüistica de ambos os grupos de utilizadores.

Esta preocupação com o aquém da ciência pode ser aproximada da pergunta que alimenta a $\mathrm{AD}$ e incide sobre a relação entre os elementos intradiscursivos (língua/ciência) e os elementos interdiscursivos (o exterior da língua/o aquém da ciência).

Esbocemos a trajetória dessa inclusão da exterioridade.

\section{Sistematização e autotelia}

Herdeiro da euforia positivista do século precedente, o início do século XX permanecerá marcado pelas tentativas de cientifizar as diferentes regiões da reflexão, garantindo-lhes métodos, leis e objetos verificáveis objetivamente. Entre a epistemologia e os estudos da linguagem, podemos citar, da década de 20 à de 30, respectivamente Círculo de Viena e o positivismo lógico; o Formalismo Russo e sua procura pela literariedade. Nosso recorte privilegia, entretanto, duas teorizações mais próximas das AD: a epistemologia bachelardiana e o convencionado marco de surgimento da lingüística moderna, o Curso de lingüistica geral, de Saussure.

Como já afirmado, a preocupação com a linguagem caracteriza um novo paradigma que nega a apreensão direta da natureza e inaugura a mediatização imperativa em todos os empreendimentos culturais. Desta perspectivas, comecemos uma leitura de Bachelard (1968, p. 15): "Tôda [sic] verdade nova nasce apesar da evidência, tôda [sic] experiência nova nasce apesar da experiência imediata".

No epistemólogo francês, a questão da ruptura elege a linguagem como medium: o projeto científico exige tanto o abandono da experiência comum quanto a complexização pela demonstração do real sempre mediada pela linguagem científica, rigorosamente construída e, portanto, superior.

Tal linguagem implicaria, ademais, uma verificabilidade daqueles que dominariam o código: "A objetividade não pode se destacar dos caracteres sociais da prova. Não se pode chegar à objetividade senão expondo de maneira discursiva e detalhada o método de objetivação.” (BACHELARD, 1968, p. 18) 
Relacionemos estas proposições às de Saussure (1972), para quem os meios de expressão sociais repousariam na convenção, no arbítrio cultural. Lembrando ainda a sugestão do genebrino da constituição do objeto pelo método, podemos inferir em ambas as posições a cisão da natureza primeira efetuada pela linguagem: em Bachelard, a mediação do objeto pela linguagem; em Saussure, a convenção instaurando a possibilidade de toda linguagem.

Da mesma maneira, o caráter social aparece nos dois textos: a prova é de caráter social, a língua produto do hábito, ou, numa definição célebre, um tesouro criado pela coletividade.Indo adiante na categoria social, leiamos novamente Saussure (1972, p. 100): “O sistema nunca se modifica diretamente; em si mesmo é imutável; apenas alguns elementos são alterados sem atenção à solidariedade que os liga a todos."

Neste caso, as chamadas "deteorizações" serão excluídas do sistema cognoscível - deixadas à margem no conceito de parole - não sendo capazes de ação positiva sobre a estrutura, a langue abstrata. Aqui, é o movimento da abstração às práticas que deve ser considerado, jamais a influência destas sobre aquelas.

Comparemos com outro trecho de Bachelard (1968, p. 136): "Com efeito, é a própria idéia de perturbação que deve ser cedo ou tarde eliminada. Não se deverá mais falar de leis simples que seriam perturbadas, mas de leis complexas e orgânicas às vezes tocadas de certas viscosidades, de certos apagamentos."

Não obstante a crítica ao cartesianismo simplificador, o que temos em Bachelard não é um aporte do social constitutivo: a exterioridade não influi diretamente nas práticas da ciência: a prova social ocorre entre iniciados na prosa da linguagem científica, experts (os que "dominam o código") interpretadores que rompem com os imediatismos do senso comum.

Além disso, as "perturbações" são devidas às próprias descobertas interiores do campo, como as teorias quânticas e sua inclusão do observador ou o abandono de uma teoria corpuscular simples. O que se tem é uma ciência que influencia privilegiadamente o entendimento da exterioridade e não uma exterioridade que fundamenta os procedimentos científicos: as "viscosidades" devem ser compreendidas e catalogadas em nome do progresso - ainda modernizante - dos conhecimentos. 
Voltando-nos à "deteorização" saussuriana, podemos vislumbrar uma similitude na ruptura que inaugura a lingüística moderna: excluindo o evento do domínio da langue, Saussure nega o historicismo precedente numa sincronia obsedante que the possibilita a construção de um modelo teórico aplicável a toda sorte desses saberes tornados linguagens. Assimilando as "diferenças" da parole numa retro-alimentação hegemônica, o estruturalismo daí nascido vai igualar a formalização à interpretação, buscando na dependência interna dos elementos os sentidos dos textos.

O que se pode aduzir do estruturalismo é menos uma intromissão de categorias estranhas aos modelos do que um voltar-se problematizador ao edifício teórico estabelecido, a fim de retificar para ratificar - seus fundamentos. Nesse projeto moderno e de autonomização, podemos incluir tanto a lógica formal de Hjelmslev e o "Círculo de Copenhagen" (1939) - tomando as reflexões epistemológicas ali suscitadas do mesmo modo que as contribuições bachelardianas - quanto os avanços sobretudo fonológicos do "Círculo de Praga" (1926) e sua sistematização profícua na criação de uma metodologia estrutural. É, contudo, a partir e no interior dessa autotelia que algumas diferenças emergirão.

\section{Paradigmas e enunciação}

Naquele que define como processos de desdogmatização da ciência, Santos (2000), define três vertentes, quais sejam:

- a nascida no interior do "Círculo de Viena" (já mencionado) nas hipóteses do chamado "segundo Wittgenstein” que, nas Investigaçôes filosóficas, efetua uma autocrítica que rompe com um entendimento unívoco do mundo mediado pela linguagem;

- aquela que é uma subversão interna da prática científica, iniciada por Ernst Mach e Bachelard e convertida tanto num convencionalismo do tipo kuhniano quanto no anarquismo metodológico professado por Feyerabend;

- a filosófica e contextualizadora, que teria como epígonos Habermas, Rorty e os hermeneutas contemporâneos. ${ }^{3}$

\footnotetext{
${ }^{3}$ Assim como Santos (2000), incluiremos a terceira vertente na pós-modernidade, incluindo aí Feyerabend.
} 
Tendo em vista o paralelo acima iniciado, lembremos da afirmação última de um caráter metalingüístico inerente à constituição dos modelos estruturais, que aproximamos de uma teleologia de ruptura na epistemologia bachelardiana. Retomando a discussão, é na segunda vertente da desdogmatização científica que encontraremos relações com as teorias enunciativas e uma primeira definição do discurso.

\subsection{Kuhn: enunciação e pragmática}

A definição de paradigma dada por Kuhn (1998, p. 13) estabelece: "Considero 'paradigmas' as realizações científicas universalmente reconhecidas que, durante algum tempo, fornecem problemas e soluções modelares para uma comunidade de praticantes de uma ciência."

A submissão do reconhecimento ao tempo faz pensar, imediatamente, na não cumulatividade e, por extensão, num rompimento tanto com o valor intrínseco do progresso quanto com o essencialismo das descobertas: os paradigmas seriam modelos que forneceriam à ciência seus critérios de legitimidade, e não subsunções diretamente provindas da natureza. A "interferência" entre sujeito e objeto, assim como em Bachelard, se dá primeiramente pela mediação lingüística: a subjetividade estaria condicionada tanto pelos caracteres de sua percepção particular quanto pelos conceitos pré-existentes, instaurando a visibilidade de certo objeto, de acordo com o paradigmasubstrato.

É na consideração da comunidade, entretanto, que o domínio da linguagem eidética é superado: se a ciência é não-cumulativa, tal ocorre porque as teorias não evoluem rumo a um optimum de apreensão dos objetos naturais, mas porque são concorrentes entre si e, portanto, necessariamente incomensuráveis; uma teoria não aprimora a outra, mas a substitui dentro dos procedimentos da ciência normal.

Quando, pois, Kuhn aponta critérios argumentativos, ligados a uma eficácia lingüística promotora da adoção de um modelo/ paradigma - não obstante a concorrência com noções internas como Lógica e natureza - acaba estabelecendo uma pragmática orientadora da ciência: o discurso científico definir-se-ia mais pela capacidade de angariar adesão a seus lances do que pelo valor do intrínseco de suas descobertas. 
Subsumido como jogo, o discurso científico não prescindiria de regras e contratos que demandariam certos compromissos de seus participantes. A evolução em busca da verdade seria suplantada por uma "vontade de saber" preexistente e implacável. Em termos de linguagem, uma pragmática dos participantes e um apontamento de suas enunciações determinaria qualquer prática da ciência.

\subsection{Benveniste: enunciação e discurso}

De acordo com Possenti (1988, p. 48), "A lingüística da enunciação tem suas origens na análise dos SHIFFTERS (Jakobson), dos performativos (Austin), e da categoria de pessoa (Benveniste)".

Excluídos pelo formalismo estruturalista, tanto a enunciação quanto o co-extensivo discurso teriam vindo à tona a partir do entendimento do falante como usuário das virtualidades do sistema.

Paralela à negação kuhniana de um próprio para a Ciência a partir do interior do discurso científico, pela qual uma atualização de modelos não excluiria a atividade enunciativa, as pesquisas lingüísticas partem da hegemonia autotélica - lembremos da importância de Benveniste e Jakobson enquanto epígonos do estruturalismo - para proceder a uma reavaliação dos aspectos excluídos da "inalcançável" abstração saussuriana.

Além dessa démarche enunciativa, outra característica intimamente relacionada a esta - compartilhada pelo convencionalismo kuhniano e essa revisão estrutural seria a da constituição de uma subjetividade marcada pela atividade: circunscrito pela língua/ paradigma, o cientista transforma o objeto segundo os modelos convencionados. Todavia, uma liberdade subsiste na consciência com que o pesquisador faz opções entre teorias concorrentes. Em lingüística, esta escolha dos termos in absentia garantiria a autonomia do enunciador, que, ademais, engendraria em sua enunciação um tempo e um espaço particulares (KUHN, 1998).

Protelando a discussão acerca de Austin para o próximo bloco, indiquemos a suposta filiação "subjetivista" de Jakobson e Benveniste, iniciando com o primeiro que, segundo o postulado de um crescendo de liberdade conforme os níveis lingüísticos (ausente na fonética e total na sintaxe) faria inferir imediatamente uma positivação da fala em detrimento do código (JAKOBSON, 1995). Ademais, no 
lingüista russo, na descrição funcional da linguagem os elementos de particularização da língua estão presentes, ficando a atualização determinada conforme as diversas modalidades de uso: a língua como sistema é atualizada diferencialmente e de maneira deliberada pelo falante (discurso da univocidade da consciência) em subcódigos, conforme as necessidades contextuais (JAKOBSON, 1995). ${ }^{4}$

Um qüiproquó similar entre forma e acontecimento ocorreria em Benveniste; entretanto, grande parte das reflexões infere uma espécie de superioridade - ainda que amiúde condenada - do segundo (através de uma subjetividade autônoma) em detrimento da primeira.

$\mathrm{Na}$ tentativa de esclarecer tal LIBERDADE, leiamos em Benveniste (1991, p. 286):

A lingua só é possivel porque cada locutor se apresenta com sujeito, remetendo a ele mesmo como EU no discurso. Por isso, EU propõe outra pessoa, aquela que, sendo embora exterior a 'mim', torna-se o men eco - ao qual digo TU e que me dir. TU. A polaridade das pessoas éna linguagem a condição fundamental, cujo procedimento de comunicação, de que partimos, é apenas uma conseqüência totalmente pragmática...

Esquematicamente, poderíamos aduzir do francês que:

- sendo a língua condicionada pelo uso do enunciador que diz EGO, fundamenta-se o entendimento do DISCURSO em Benveniste (1991) como ato individual de utilização da linguagem;

- na proposição de outra pessoa - TU- o EU ocupa uma posição de transcendência que, apesar da reversibilidade prevista, funda a aparição da alteridade (esquematicamente, EU precede TU);

- integrando EU-TU (enunciador-enunciatário), a alternativa pragmática fica instaurada numa perspectiva da linguagem como influenciação recíproca.

\footnotetext{
${ }^{4}$ É importante que se diga que Michel Pêcheux aproximou-se da questão enunciativa via Jakobson dada sua exclusão de Benveniste pelo caráter subjetivista-idealista. A questão dos shiffters - que apontam no enunciado a presença da enunciação - é tomada, também, de Jakobson. Conforme artigo de GADET et al . (GADET, 1990, p. 39-60).
} 
Indo adiante, essa "subjetividade da linguagem" ${ }^{5}$ adensa a autonomia, estruturando a língua (espacialização e temporalização) a partir dos operadores gramaticais da presença do EGO:

A linguagem está de tal forma organizada que permite a cada locutor APROPRIAR-SE da lingua designando-a como EU.

Os pronomes pessoais são uma parte de apoio para essa revelação da subjetividade na linguagem [...]. São os indicadores da DEÍXIS ,[...] que organizam as relações espaciais e temporais em torno do 'sujeito' tomado como ponto de referência... (BENVENISTE, 1991, p.288).

Esta transformação especificante da língua tornada discurso por um ato do sujeito é condensada por Kristeva (1999) para quem o discurso particularizaria a língua pelas marcas específicas de uma enunciação, na qual a subjetividade teria preponderância sobre os aspectos temporais e espaciais.

\subsection{Atos de fala, jogos de linguagem}

Segundo Maingueneau (1989, p. 29): “Na perspectiva pragmática, a linguagem é considerada como uma forma de ação;

\footnotetext{
${ }^{5}$ A propósito da subjetividade em Benveniste, Geraldi (1996, p. 13) sugere duas leituras :

este sujeito é livre e orienta seu discurso segundo seus interesses, mobilizando a lingua para dizer o que quer dizer- a língua como liberdade do homem - mas também, eparadoxalmente, pelo fato mesmo da existência de um aparato formal sempre presente e indicado nos enunciados, mecanismo que aparece como 'condição de emprego da lingua', esta oferecendo os instrumentos de realização da enunciação que necessariamente se dará pelo emprego das formas, pode-se imaginar seu 'quadro figurativo da enunciação' como constituidor dos lugares - 'figuras' - a serem preenchidas pelos parceiros do diálogo - a língua como prisão do homem.

Isto posto, é mister que lembremos dos paradigmas para aventar a possibilidade da negação estruturalista da $\mathrm{AD}$ como forma de marcar uma diferença argumentativa, pela qual o projeto enunciativo de Benveniste deveria ser positivado em liberdade e negativizado em determinismo.Ratificando a leitura da língua/prisão, leiamos o francês: "É na linguagem e pela linguagem que o homem se constitui como SUJEITO, porque só a linguagem fundamenta na realidade, na SUA realidade, que é a do ser, o conceito de 'ego'".
} 
cada ato de fala (batizar, permitir, mas também prometer, afirmar, interrogar, etc.) é inseparável de uma instituição, aquela a que este ato pressupõe pelo simples fato de ser realizado".

Se na teoria discursiva de Benveniste era preciso atentar para a constituição necessária de um TU pelo enunciação anterior de um EU, o imperativo da intersubjetividade constitutiva será ampliado pelas contribuições pragmáticas, cujos modelos (MAINGUENEAU, 1989) seriam o jurídico, o teatro e o jogo.

Consideramos neste trabalho as teorias de Austin, Searle e Wittgenstein como fundamentais para esta "guinada pragmática", tanto em lingüística quanto na filosofia. Não nos detendo nas especificidades de cada um dos teóricos referidos, passamos a um cômputo geral de suas contribuições axiais (para esta pesquisa), que permite aproximálos numa Teoria dos Atos de Fala:

As aproximaçôes que são estabelecidas entre Wittgeinstein e as teorias dos atos decorrem de sua preocupação em mostrar as finalidades imediatas que associamos ao uso da linguagem. No procedimento interlocutivo, as palavras representam mais do que os objetos que descrevem, do que aquilo que significam: elas servem para engendrar um conjunto de ações previstas nas circunstâncias de uso. (MARI, 2001, p.100) ${ }^{6}$

As relações intersubjetivas e contratuais dos múltiplos “jogos de linguagem" atestariam ainda uma auto-referência performativa, indicando o modo específico de compreensão e a utilização daí decorrente. Habermas (1990, p. 112) condensa tais inferências dos "jogos" que, num mesmo lance, destituiriam tanto a subjetividade quanto o objeto de conhecimento de sua essencialidade: a experiência privada seria excluída em nome de uma pré-compreensão que precede e "emoldura" qualquer entendimento do si-mesmo, o que permitiria se pensar em formas de subjetivação contextuais; o objeto do conhecimento apareceria como construto, marcado pelas determinantes contratuais cuja característica estaria na aceitabilidade em detrimento exclusão necessária - da verificabilidade.

\footnotetext{
${ }^{6} \mathrm{O}$ artigo em questão é o de Hugo Mari, Atos de fala : notas sobre origens, fundamentos e estrutura, presente na coletânea Mari (2001), p. 93-131.
} 
É dessa intersubjetividade estratégica e persuasiva que, parecenos, tratam Austin e Searle. Assim, quando o último formula pelos performativos as implicações pragmáticas dos procedimentos (dizer $=$ fazer), ou quando Austin relaciona a conteúdos proposicionais forças ilocucionais (MARI, 2001), o que se tem é uma extrapolação da autotelia lingüística e sua abstração e a exigência de um debate acerca da interação constitutiva da linguagem.

Isto posto, é preciso que façamos um balanço prévio em nosso corpus: enquanto o binômio epistemologia/lingüística de Bachelard/Saussure insistia na tentativa de neutralizar as relações entre sistema e exterioridade, o que temos em Kuhn/pragmática é uma cisão pela qual influenciação e "comunidades" suplantariam a lógica objetiva da linguagem.

\section{Discurso e anarquia}

Já numa preliminar abordagem direta da AD, situemos Michel Pêcheux (doravante MP) na discussão lingüística do final da década de sessenta: filósofo ligado ao Partido Comunista e ao círculo de Althusser e a pressuposição inicial de corte epistemológico, MP pretendia empreender uma reformulação na Lingüística estrutural - "ciência piloto" então desgastada - que a tornasse instrumento político para a transformação das relações sociais.

Se, como afirmamos, uma guinada ocorreu com a assunção de um paradigma lingüístico para a epistemologia (bem como para outras esferas do saber), é numa complexização - já observada - dos próprios modelos lingüísticos que notaremos, a partir dessa pósmodernidade, o encaminhamento das discussões, desta feita acerca da materialidade da língua e, por conseguinte, das linguagens científicas. A relação entre os objetos, os conceitos e os tipos de subjetividade, como fez notar Orlandi (1999), será posta em cheque, pela consideração material da produção de qualquer objeto de conhecimento

A crítica à evidência na datidade dos objetos é similar àquela vislumbrada pela crítica dos sentidos lingüísticos na $\mathrm{AD}$, especificadas por Orlandi (1999): negação do sujeito como fonte do sentido; assujeitamento ideológico; exterioridade na base de todo dizível. Conforme Henry (1992, p. 140): 
Considerar assim o sentido indica que ele não pode estar relacionado com a forma-sujeito 'individuo-sujeito', ser procurado nas palavras, no texto ou no discurso de um indivíduo, mas na relação desse texto, dessas palavras, desse discurso individual com outros textos, outras palavras, outros discursos, relação na qual esse sentido se constitui enquanto efeito ideológico

$\mathrm{Na}$ indissolúvel relação entre discursos e práticas sociais e numa preocupação anti-antropológica do entendimento dessa língua transformada em discurso é que, dentro dos limites impostos pelo nosso recorte, traçamos um paralelo entre o anarquismo epistemológico de Feyerabend e a arqueologia foucaultiana com a AD, apontando em ambas a materialidade como característica fundamental, bem como a rigidez de sua destruição dos sistemas.

\subsection{Anarquia e arqueologia}

A negação dos métodos da ciência normal em nome de uma anarquia dos procedimentos é a base da contribuição de Feyerabend que, no entanto, está aqui descrita a partir de outra problematização, a saber, acerca do papel da interpretação sóciohistoricamente localizável de qualquer fato científico.

Abandonando tanto a identidade do objeto (natural $\mathrm{X}$ do conhecimento) quanto as pressuposições da ordem interna do discurso científico, a atividade da epistemologia residiria na descrição dessas interpretações, entendidas em seu caráter mutável de percepções determinadas pelas condições de emergência sociais de conceitos e objetos, excluindo prováveis distinções de ordem axiológica entre a ciência e o mito:

A ciência é uma das muitas formas de pensamento desenvolvidas pelo homem e não necessariamente a melhor. Chama a atenção, é ruidosa e imprudente, mas só inerentemente superior aos olhos daqueles que já hajam dividido favoravelmente a certa ideologia ou que já a tenham aceito, sem querer examinar suas conveniências e limitações. (FEYERABEND, 1977, p. 447)

O projeto iluminista de uma racionalidade onipresente transubstanciada em ciência surgiria como uma dogmática: é só 
procedendo a uma inversão ideologizante que se poderia tomar o discurso científico como acesso privilegiado à verdade última do mundo. O projeto anarquista aproximar-se-ia às preocupações marxianas de uma determinação material das consciências, pela qual a ciência não seria considerada, a partir da dicotomia teoria $\mathrm{x}$ prática, como produção abstrata de conceitos, mas determinada pela materialidade em que está - obrigatoriamente - inscrita. ${ }^{7}$

Subsumida também como representação de um grupo social, a circularidade da ciência estaria fundamentada na manutenção das estruturas que a permitem existir e para as quais formularia os critérios de validação. Em Feyerabend (1977), as abstrações universalizantes do discurso científico teriam, então, o sentido negativo da ideologia marxiana, sobretudo quando esse é tomado como metateoria.

Diferentemente dos paradigmas kuhnianos, os modelos são negados em nome do anarquismo e da contra-indução na própria sistematicidade estabelecida, próxima da crítica ao estruturalismo feita pela AD.

Retrospectivamente, o que podemos aduzir da epistemologia até o momento é a negação da cumulatividade - rupturas tornam paradigmas incomensuráveis entre si- e a importância crescente das descontinuidades - internas em Bachelard, pragmáticas em Kuhn, ideológicas em Feyerabend. A arqueologia de Foucault inscreve-se nessa inclusão do descontínuo, pela qual se deu "sua passagem do obstáculo à prática; sua integração no discurso dos historiadores no qual não desempenha mais o papel de uma fatalidade exterior que é preciso reduzir, e sim de um conceito operatório que se utiliza" (FOUCAULT, 1997, p. 10-11).

Todavia, o abandono de Foucault é, ainda, o de um aprofundamento progressivo da negação da noção de verdade e do critério privilegiado de avaliação nos entendimentos de uma atualidade, visto que os parâmetros de avaliação são contemporâneos de cada configuração de saber : a validação das teorias não se daria pela

\footnotetext{
${ }^{7}$ Araújo (1998), entretanto, não relaciona Feyerabend ao materialismo dialético. Se tal propomos, é tanto pelo uso da categorias marxianas- sobretudo a de ideologia - quanto pelas recorrentes menções à Lênin no corpo do texto, além, evidentemente, duma abordagem que, nos parece, sugere o caráter superestrutural da ciência.
} 
perspectiva do tempo organizador de fases de desenvolvimento, sendo que à arqueologia seria prescrito investigar influências recíprocas em cada corte sincrônico, indicando nestes os a priori específicos da ordem do discurso vigente- que circunscreveria os objetos, subjetividades e conceitos possíveis e aqueles interditos (MACHADO, 1988).

Deste modo, as rupturas não poderiam se dar entre teorias concorrentes, mas num outro nível, o das próprias configurações do saber (epistemes resultantes dos A PRIORI), que retiram das ciências suas pretensões essencialistas, posto que outros saberes compartilham desta mesma configuração: "existem, lado a lado, outros tipos de discursos e práticas, cuja importância para nossa sociedade e para nossa história independe do estatuto de ciência que possam vir a receber." (FOUCAULT, 1996, p. 35).

Este abandono da continuidade e do redimensionamento da ruptura possibilitariam tanto aquela incredulidade diante dos metarrelatos - sempre às voltas com "regimes" de dizer - quanto o conseqüente movimento de negação antropológica, dada a complementaridade de ambos.

De um tempo enunciativo organizador do sistema lingüístico em Benveniste, o que temos em Foucault é uma negação da subjetividade - o homem é um evento nascido na configuração moderna dos saberes - como síntese dos conhecimentos possíveis e sua afirmação como finitude empírica que garante a positividade de um saber sempre - já mediado pelas formas históricas da produção, da vida e da linguagem (ARAÚJO, 2000).

\section{$4.2 \mathrm{O}$ surgimento da $\mathrm{AD}$}

Uma aproximação entre a arqueologia foucaultiana e as teorias materialista-dialéticas certamente merecem acuidade, sobretudo pela negação arqueológica das relações necessárias entre o EXTERIOR (práticas sociais) e o INTERIOR (discurso), ou, no jargão marxista, entre estrutura e superestrutura.

$\mathrm{Na}$ esteira dessas diferenças, é esclarecedor apontar os fatores micro-operacionais de Foucault: ainda que admita, de alguma maneira (ainda que implícita) a existência de cortes, de rupturas, esses não se dão nem pela negação de um estado ideológico precedente, muito menos na totalidade dos saberes, estando sempre baseados em 
incomensurabilidades específicas e contextuais. No caso do marxismo, a suposição estaria numa ciência da história - corte diante da ideologiae no determinismo binarista entre estrutura econômica e superestrutura discursivo-ideológica.

É preciso, pois, que se aponte um substrato comum das teorias marxistas - e a AD estaria aí incluída como manifestação lingüística da problemática althusseriana - e o empreendimento arqueológico de Foucault, qual seja: a heterogeneidade intrínseca aos sistemas de significação e a pluralidade de lugares que interditam o reino da sinonímia e inauguram o da paráfrase, sempre localizável num espaço-tempo e, portanto, contextual.

Dessa perspectiva é que se sugere a leitura de Pêcheux e Fuchs (1990) quando erige através do discurso a formulação de um objeto sócio-histórico onde o lingüístico interviria como pressuposto, sendo na insuficiência de um sistema semiológico auto-referente fundada a $\mathrm{AD}$, como forma de "aplicação da teoria lingüística em um CAMPO EXTERIOR” (PÊCHEUX, 1990, p.185).

Nos dois casos, não se teria transformação interna possível de qualquer sistema - nem, por extensão, progresso como aprimoramento ou cumulatividade - mas cortes pelos quais os sistemas, compósitos de materialidades contextuais, engendrariam incomensuráveis paráfrases que, no mesmo movimento em que proibiriam a essencialidade de uma verdade, apontariam os seus possíveis enunciativos (dizer algo como a exclusão do discurso-outro).

Seria, pois, naquela pós-modernidade aventada de antemão que "catalogaríamos", didaticamente, estes debates, não obstante a necessária especificidade de cada um deles: ambos partiriam de uma negação do inerente à subjetividade, bem como ao correlato desenvolvimento das ditas ciências humanas que se ancoram nesse duplo "empírico transcendental" que é o homem (tomado como objeto das ciências humanas): elemento sobre o qual se debruçam as humanidades na busca de um em-si mas que só é pensável, contudo, no interior de discursos inseridos na materialidade das práticas da linguagem, do trabalho e da vida (FOUCAULT, 1981).

Destarte, se à inteligibilidade desse objeto-homem corresponderia à das ciências humanas, a atitude anti-humanista de Marx (tratar a consciência como determinada pela exterioridade) estaria imediatamente relacionada à foucaultiana: negá-lo (o homem) como 
próprio é pôr em cheque o valor heurístico das "humanidades"e, a partir daí, discutir a própria teleologia das ciências como forma de realização numa realidade ideal. É considerar o aquém dos sistemas diretamente proporcional à impossibilidade de metalinguagens.

\section{Considerações finais}

A chamada guinada lingüística iniciada a partir do logicismo e responsável pelo esvaziamento da subjetividade transcendental em sentenças gramaticais teve entre suas repercussões o entendimento dos saberes como linguagens que, se num primeiro momento foram entendidas como sistemas autônomos, passariam a ser indagados em sua fragilidade mediante a multiplicidade de fatores com os quais mantinham contato.

Assim, no mesmo movimento em que se torna a questão nodal dos debates, a linguagem passa a responder pelas diferenças sempre presentes em qualquer das estruturas, fazendo emergir a desconfiança para com os metarrelatos e a impossibilidade de esgotar os objetos de conhecimento.

Enquanto ferramenta de todo saber, a mesma linguagem se apresenta cindida, pautada não por dependências internas e subsumíveis mas por séries de dispersões que, menos que exceções, se mostram como regras inefáveis de toda manifestação discursiva.

Nesse panorama que aqui apresentamos como pós-moderno, a contribuição da AD-1 de Michel Pêcheux residiria justamente no negar um princípio explicativo único baseado na imanência do campo autônomo, nos moldes modernos: os sentidos do texto estão sempre inseridos numa relação constitutiva com a alteridade.

Destarte, ainda que num primeiro instante (AD-1) o corte cientificista althusseriano permaneceria no reconhecimento de um metalugar cuja função era desmascarar as simplificações ideológicas, a constituição de uma AD-2 e seus reflexos permitiria um acréscimo pós-modernizante à $\mathrm{AD}$, trazendo à tona questões como interdiscurso e dispersão que, tomadas de Foucault, apontariam (ao menos) os caminhos possíveis para uma salutar revisão. 


\section{Referências}

ARAÚJO, Inês Lacerda. Foucault e a crítica do sujeito. Curitiba: Editora da UFPR, 2000. 220p.

. Introdução à filosofia da ciência. 2. ed. Curitiba: Editora da UFPR, 1998. 233p.

BACHELARD, Gaston. O novo espíito cientifico. Trad. Juvenal Hahne Júnior. Rio de Janeiro: Tempo Brasileiro, 1968. 151p.

BENVENISTE, Émile. Problemas de lingüistica geral I. 3. ed. Trad. Maria da Glória Novak; Maria Luiza Neri. Campinas: Pontes/ Editora da UNICAMP, 1991. 387p.

FEYERABEND, Paul. Contra o método. Trad. Octamy S. da Mota; Leônidas Hegenberg. Rio de Janeiro: Francisco Alves, 1977. 488p.

FOUCAULT, Michel. A ordem do discurso. 8. ed. Trad. Laura Fraga de Almeida Sampaio. São Paulo: Loyola, 2002. 79p.

407p.

. As palavras e as coisas. 2. ed. São Paulo: Martins Fontes, 1981.

HABERMAS, Jürgen. Pensamento pós-metafísico: estudos filosóficos. Trad. Flávio Breno Siebeneichler. Rio de Janeiro: Tempo Brasileiro, 1990. $271 \mathrm{p}$.

HENRY, Paul. A ferramenta imperfeita: língua, sujeito e discurso. Trad. Maria Fausta Pereira de Castro. Campinas: Editora da UNICAMP, 1992. 241p.

KUHN, Thomas S. A estrutura das revoluções científicas. 5. ed. Trad. Beatriz Vianna Boeira; Nelson Boeira. São Paulo: Perspectiva: 1998. 257p.

KRISTEVA, Julia. História da linguagem. Trad. Maria Margarida Barafona. Lisboa: Edições 70, 1999. 377p. 
JAKOBSON, Roman. Lingüistica e comunicaşão. 15. ed. Trad. Izidoro Blikstein e José Paulo Paes. São Paulo: Cultrix, 1995. 162p.

LYOTARD, Jean François. A condição pós-moderna. 5. ed. Trad. Ricardo Corrêa Barbosa. Rio de Janeiro: José Olympio, 1998. 131p.

MACHADO, Roberto. Ciência e saber: a trajetória da arqueologia de Michel Foucault. 2. ed. Rio de Janeiro: Graal, 1988. 217p.

MAINGUENEAU, Dominique. Novas tendências em análise do discurso. Trad. Freda Indursky. Campinas: Pontes/Editora da UNICAMP, 1989. 198p.

MARI, Hugo (Org.). Análise do discurso: fundamentos e práticas. Belo Horizonte: Núcleo de Análise do Discurso/FALE/UFMG, 2001.360p.

ORLANDI, Eni Pulcinelli. Análise do discurso: princípios e procedimentos. Campinas: Pontes, 1999. 100p.

PÊCHEUX, Michel. Análise automática do discurso. In: GADET, F.; HAK, T. (Orgs.). Por uma análise automática do discurso: uma introdução à obra de Michel Pêcheux. Trad. Bethania S. Mariani et al. Campinas: Editora da UNICAMP, 1990. p.61-163.

.; FUCHS, Catherine. A propósito da análise automática do discurso: atualização e perspectivas. In: GADET, F.; HAK, T. (Orgs.). Por uma análise automática do discurso: uma introdução à obra de Michel Pêcheux. Trad. Bethania S. Mariani et al. Campinas: Editora da UNICAMP, 1990. p. 163-252.

PINTO, Joana Plaza. Pragmática. In: MUSSALIM, F; BENTES, A. C. (Orgs.) Introdução à lingüística: domínios e fronteiras. v. 2. 2. ed. São Paulo: Cortez, 2001. p. 47- 68.

POSSENTI, Sírio. Discurso, estilo e subjetividade. São Paulo: Martins Fontes, 1988. 218p. 
RABUSKE, Edvino. Epistemologia das ciências humanas. Caxias do Sul: EDUCS, 1987. 152p.

SANTOS, Boaventura Souza. Introdução à uma ciência pós-moderna. 3. ed. Rio de Janeiro: Graal, 2000. 176p.

SAUSSURE, Ferdinand de. Curso de lingüistica geral. 4. ed. Trad. Antonio Chelini; José Paulo Paes; Izidoro Blikstein. São Paulo: Cultrix, 1972. $279 \mathrm{p}$. 